\title{
Tchékhov e o teatro brasileiro
}

Chekhov and the Brazilian theater

\section{Rodrigo Alves do Nascimento}

Rodrigo Alves do Nascimento Doutorando do PPG em Literatura e Cultura Russa na Faculdade de Filosofia, Letras e Ciências Humanas da Universidade de São Paulo (FFLCH-USP)

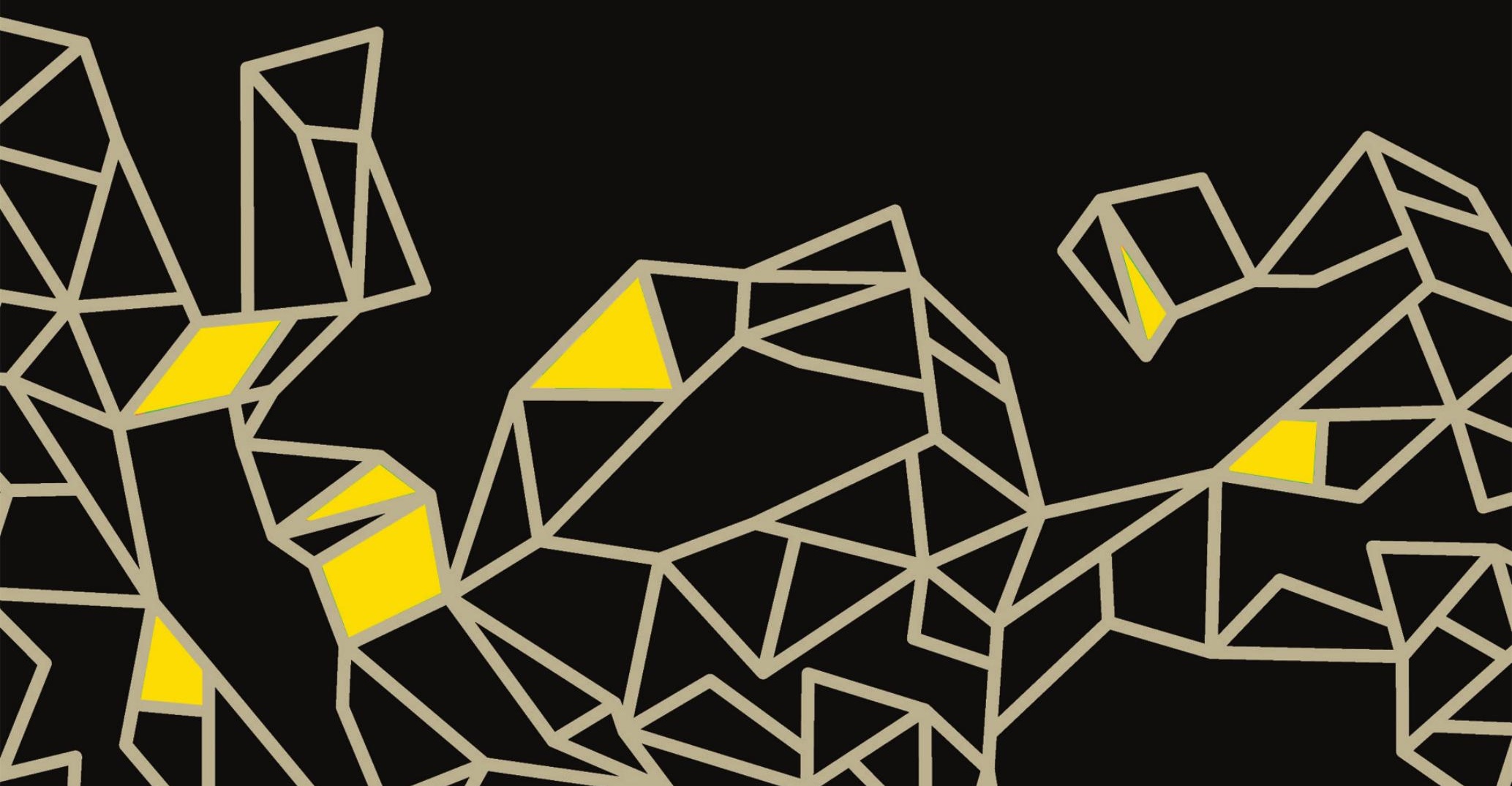




\section{Resumo}

A recepção das peças Anton Tchékhov no Brasil é atravessada pelos principais impasses e debates que marcaram nossa história teatral dos últimos 80 anos. Ainda que reconhecido como peça chave do drama moderno, sua dramaturgia passou por uma tardia e irregular recepção nos palcos brasileiros. Neste artigo, comentarei panoramicamente essa trajetória e ao final apresentarei uma lista de suas encenações, em um esforço historiográfico e interpretativo que vai das primeiras montagens de suas peças nos anos 1940 até as encenações desconstrucionistas no início do século XXI. A partir da seleção de espetáculos e textos críticos emblemáticos, será possível ver como uma espécie de "tchekhovismo", herança direta da leitura stanislavskiana, reboou entre diretores e críticos e foi paulatinamente problematizado a partir dos anos 1960.

Palavras-chave: Anton Tchékhov, Recepção, Teatro brasileiro.

\section{Abstract}

The reception of Chekhov's plays in Brazil involved the main impasses and debates that have marked our theatrical history in the last eighty years. Although recognized as a decisive playwright for the understanding of the theatrical modernity, his plays went through a late and an irregular reception process in the Brazilian stage. In this article, I intend to comment this trajectory and, then, to present a list of performances, in a historiographical and interpretative effort that goes from the first amateur performances in the 1940s to the deconstructionist performances in the beginning of the 21st century. From the selection of emblematic performances and critical texts, it will be possible to see how a sort of "chekhovism", as a direct inheritance of the Stanislavskian reading, resounded among directors, actors, and critics and was gradually questioned from the 60 s on.

Keywords: Anton Chekhov, Reception, Brazilian theater.

Anton Tchékhov protagonizou com Ibsen, Maeterlinck, Hauptmann e Strindberg uma verdadeira desestabilização das formas dramáticas em fins do século XIX. Já no início do século XX suas peças longas ganharam os principais palcos da Europa e dos Estados Unidos, mas durante muito tempo 
no Brasil o dramaturgo foi considerado um autor difícil e estranho à nossa cultura. De modo geral, era relacionado a peças sem ação dramática clara, lentas, melancólicas, de mensagem difusa - verdadeiro protótipo da insondável "alma eslava".

Vistas com as lentes de hoje tais leituras parecem bastante redutoras, mas a verdade é que elas circularam de maneira expressiva entre diretores, atores e críticos até pelo menos a década de 1980 - momento em que, de modo mais ou menos consensual, Tchékhov já era considerado parada obrigatória na formação ou produção de diretores e atores. De início, críticos e muitos artistas nacionais adotaram os mesmos termos de críticos russos de fins do XIX. Incomodavam-se com o aparente desleixo do dramaturgo diante das leis mais elementares do drama. Segundo eles, em suas peças "nada acontecia" e não havia qualquer conteúdo produtivo (ANIKST, 1972, p. 571).

Ocorre que mesmo na Rússia as peças inéditas e polêmicas de Tchékhov só ganharam suporte para interpretações mais elaboradas quando encenadas pelo Teatro de Arte de Moscou (TAM), o único então capaz de captar aquilo que Nemiróvitch-Dântchenko (1919, p. 10) chamou de "corrente subterrânea" (podvodnoie tetchênie) da dramaturgia tchekhoviana. Suas peças longas foram laboratório para a formação de parte das ideias cênicas de Konstantin Stanislávski, tais como a necessidade de unidade dos elementos cênicos, o planejamento antecipado dos detalhes da encenação e a própria noção de subtexto e ação interna - todas formulações fundamentais para a compreensão das tendências e debates teatrais de todo o século $X X$.

O TAM percebeu que o verdadeiro demônio das peças de Tchékhov estava nos detalhes. Para eles, os diálogos e comportamentos aparentemente ilógicos das personagens configuravam apenas uma superfície do drama, pois os verdadeiros conflitos aconteciam nas entrelinhas ou offstage. A ação em Tchékhov seria indireta e dependeria da associação dos detalhes ao conjunto (MAGARSHACK, 1952, p. 159-173). Do mesmo modo, as frases aparentemente sem sentido proferidas pelas personagens, os tiques, as citações e, no seu extremo oposto, o discurso grandiloquente e pretensamente filosófico que declamam, revelam mais sobre suas máscaras sociais, seu isolamento e seus automatismos cotidianos do que sobre aquilo que anunciam. Elas seriam sinais do edifício de automistificação a que cada um se submeteu, 
demonstrações da inabilidade generalizada para a vida prática, que Ihes dá, em muitos casos, desenho finamente clownesco. Em meio a seus desejos e memórias que não se desenvolvem em diálogos e ações diretas, emergiria a famosa "pausa techekhoviana", a qual, segundo Nemiróvitch-Dântchenko, possuía papel ativo na intensificação da experiência dessas personagens (NEMIRÓVITCH-DÂNTCHENKO, 1937, p. 163).

Assim, a aguda leitura dos diretores russos, somada à desbravadora proposta cênica em desenvolvimento no TAM, conseguiu consolidar algumas linhas de interpretação que, como vemos, perduraram até recentemente. Em seus espetáculos, as peças de Tchékhov se tornaram símbolos de um certo "tédio de província", da "impotência ante os grandes sonhos" e da "melancolia ante a vida que se esvai". Isso implicou, em termos cênicos, a adoção de procedimentos então revolucionários, como a concepção de suas peças em termos de sinfonia musical, combinando a um só tempo uma atmosfera específica e os detalhes sugestivos. E se em alguns momentos tais leituras incomodaram ao próprio Tchékhov, o que sabemos é que após as turnês do TAM muitas delas seriam trabalhadas na Rússia e internacionalmente como ideias tipicamente techekhovianas. Essa tipificação cristalizou em epígonos do Teatro de Arte aquilo que chamamos aqui de "tchekhovismo", o qual percorreu os palcos franceses, britânicos, estadunidenses e chegou completamente aderido às suas peças no Brasil, como um programa a ser aplicado.

Tal tchekhovismo, reforçado por diretores como Boleslávski nos Estados Unidos, Komissarjévski no Reino Unido, Ludmila e Gerogy Ptoëf na França, alcançou seu pico nos anos 1930 e 1940, momento em que Tchékhov estava apenas começando a ser traduzido no Brasil (NASCIMENTO, 2013b). No que se refere à dramaturgia do autor, sua introdução sofreu com o ritmo irregular de nossa cena nos anos 1930 e 1940. Diferentemente de outras artes, nosso teatro não participou do clima renovador em torno da Semana de Arte Moderna de 1922 e ainda estava muito concentrado nas produções em torno das grandes estrelas, bem como nos repertórios cômicos e melodramáticos de bilheteria garantida (PRADO, 1993). No entanto, é justamente fora do circuito oficial que emergiram importantes movimentos de arejamento.

A primeira encenação de Tchékhov da qual temos registro é $O$ urso, dirigida por Hermilo Borba, no Recife, em 1946, pelo Teatro dos Estudantes 
de Pernambuco (TEP). A proposta do grupo era criar uma alternativa de raízes populares, que se contrapusesse às peças burguesas e sentimentais que dominavam o repertório da capital. Na Biblioteca da Faculdade de Direito improvisou-se um palco sobre mesas, com cenário desproporcional e resistente à configuração da famosa "sala gabinete". Fugiram dos clichês do tradicional vaudeville, pois para o grupo o mais importante era explorar o dinamismo dos diálogos e os quiproquós também típicos da comédia brasileira.

Apesar da recepção modesta, mas calorosa, já há aqui um importante sinal do que seria a recepção de Tchékhov nesses anos iniciais: ao invés de peças longas, como As três irmãs, suas peças em um ato foram mais populares. De 1946 a 1954 houve quatro encenações de $O$ urso e oito encenações de O pedido de casamento em São Paulo, Rio de Janeiro, Recife, Salvador e Porto Alegre - todas por grupos estudantis e amadores. De modo geral, o tamanho reduzido dessas farsas em um ato facilitava a condução de ensaios e mesmo a improvisação de espaços para apresentação. Além disso, o dinamismo dos diálogos, como também a comicidade nada apelativa e por vezes temperada de trágico ofereciam um prato cheio para os grupos em busca de formas arejadas fora dos roteiros batidos das encenações vigentes. Assim, Tchékhov se tornava uma alternativa ao simples entretenimento de boulevard praticado pelo teatro tradicional e um bom laboratório para o exercício de uma linguagem arejada e moderna. No programa do espetáculo com peças em um ato, intitulado "Festival Tchékhov", dirigido por Luiz Carlos Maciel e realizado em abril de 1962 em Salvador, lia-se:

Não nos preocupam, nessas farsas, os famosos estados de alma tchekhovianos. Nelas, Tchékhov revive a tradição de um teatro popular: o da comicidade crua e direta e da expressão simples e imediata. Seu valor fundamental é a vitalidade frenética que as anima. Esse foi o valor fundamental escolhido para ser projetado para a plateia pelo espetáculo. Trata-se de fazer justiça não a um Tchékhov metafísico, convertido pela generalização teórica numa ideia platônica, mas a um Tchékhov real, i.e. aos termos em que se manifesta a vida de suas peças. (FESTIVAL TCHÉKHOV, 1962)

Por outro lado, o teatro profissional ignorou as pequenas farsas de Tchékhov de maneira quase completa até os anos 1980. Isso aconteceu muito 
provavelmente porque tais peças não estavam ligadas ao que era considerado pela crítica como "tipicamente tchekhoviano", do mesmo modo que a comédia leve era vista como gênero menor - com exceção da primeira montagem de uma peça em um ato feita pelo Teatro Brasileiro de Comédia (TBC), em 1950. A montagem de Um pedido de casamento (Figura 1), dirigida pelo italiano Adolfo Celi, foi apresentada no mesmo espetáculo com a peça Huis Clos, de Sartre, e considerada por muitos apenas como um digestivo de fim de noite, dado o caráter ácido e polêmico da peça do dramaturgo francês, a qual havia sido julgada imoral e unificou, ao mesmo tempo, as vozes contrárias da Igreja e do Partido Comunista. Na direção, o diretor Adolfo Celi acentuou o caráter farsesco de "comédia de pastelão com grandes barbas postiças e belíssimos fraques de ocasião" (PRADO, 1956, p. 249-251). Décio de Almeida Prado censuraria o peso farsesco dado pelo diretor à montagem da peça de Tchékhov, que pareceu criar a sensação de que os atores encenavam contra seus personagens, e não com eles, além de acentuar o exotismo russo (Ibid., loc. cit.).

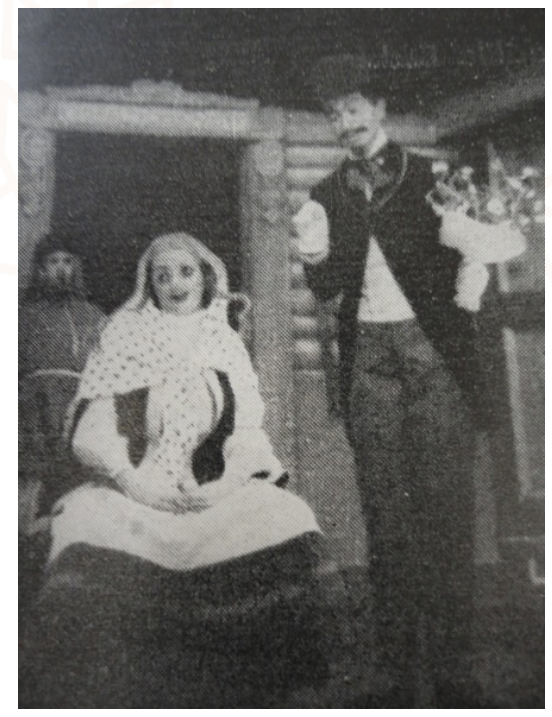

Figura 1 - Cena de O pedido de casamento, pelo TBC, sob direção de Adolfo Celi, em 1950. Da esquerda para a direita,Tchubúkov (Waldermar Wey), Natália Stepánovna (Célia Biar) e Ivan Vassílievitch Lomóv (Ruy Affonso).

Foto: Teatro Brasileiro de Comédia, 1954.

Já suas peças longas, como Tio Vânia e Jardim das cerejeiras, eram assunto de conversas restritas entre aqueles que tiveram a oportunidade de assistir à breve temporada de La cerisaie, da companhia francesa Louis 
Barrault-Madeleine Renaud em 1954, ou entre os que já tinham assistido a alguma peça de Tchékhov no exterior. Até meados da década de 1950 ainda não havia em circulação nenhuma tradução em edição brasileira de tais textos, sequer em tradução informal de grupos teatrais. Em comentários críticos, a referência a elas emergia rapidamente e já com alguma cristalização. Ecos do tchekhovismo antecipavam-se à sua própria chegada nos palcos. Na temporada carioca de $O$ pedido de casamento, Ziembínski, o diretor responsável por essa montagem do TBC, assim se referiu à peça: "nada se encontra no 'O Pedido de Casamento' daquela íntima e crepuscular melancolia tão querida ao autor de 'Tio Vânia”" (TEATRO BRASILEIRO DE COMÉDIA, 1954, p. 16). Ora, não seria exagero dizer que, lido em tal chave, qualquer grupo teatral brasileiro nesse período encararia Tchékhov com sérias restrições. Afinal, ao longo dos anos 1950, o teatro brasileiro sofreria constantemente com as pressões de bilheteria, a falta de sistematicidade dos trabalhos e as dificuldades de organização. Suas peças poderiam ser, portanto, sinônimo de fracasso financeiro.

Por isso mesmo foi que um grupo amador sério como $\mathrm{O}$ Tablado (RJ), programaticamente afastado do repertório fácil e das pressões de bilheteria, encenaria Tio Vânia em 1955. O diretor Geraldo Queiroz tentou a todo custo fugir dos ritmos lentos. Em entrevista, afirmou que "os grupos amadores [...] podem obter de Tchékhov espetáculos muito mais homogêneos que grandes elencos, onde cada grande ator procura projetar mais alto a sua interpretação," e que a orientação que os guiava era a de "buscar o ritmo mais adequado dentro de sua linha" (TIO VÂNIA..., 1955, p. 4). Muito dessa concepção advinha das experiências do diretor Geraldo Queiroz com as encenações vistas na Europa. No entanto, o crítico Paulo Francis se lembraria de que a montagem realizou o contrário: seu ritmo lento fazia com que a expressão "alma eslava" emergisse na cabeça dos espectadores a todo momento durante a encenação. Segundo ele, a tentativa de substituir o excesso de trivialidade da vida daquelas personagens com silêncios abusivos criava uma falsa grandeza, buscando efeitos onde não havia (FRANCIS, 1966, p. 117-126). Na mesma linha de interpretação veio a montagem de As três irmãs (Figura 2), feita por um grupo estudantil da Escola de Arte Dramática (EAD), em 1956, e dirigida por Alfredo Mesquita. O ritmo geral era de lentidão e a concepção abertamente trágica. 


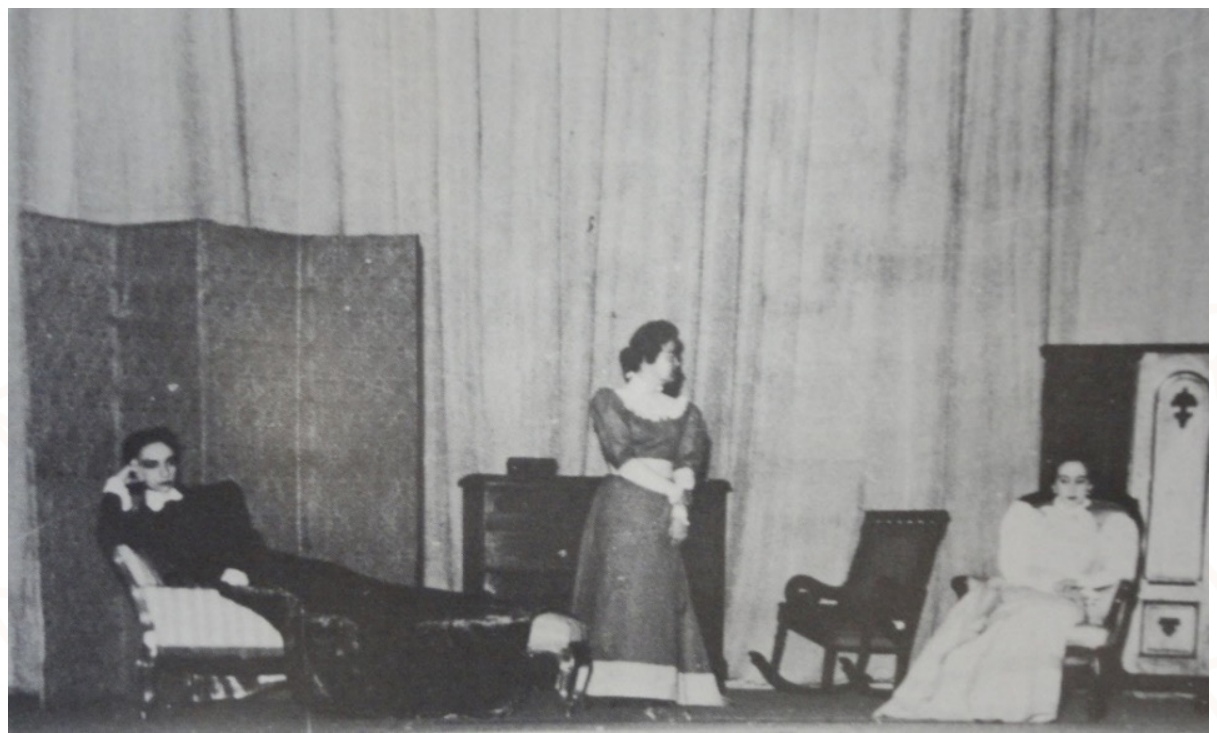

Figura 2 - Cena de As três irmãs, pela EAD, sob direção de Alfredo Mesquita, em 1956. Da esquerda para a direita, Macha (Cândida Teixeira), Olga (Cecília Carneiro) e Irina (Glória Sampaio). Foto: Arquivo EAD, 1956.

De qualquer maneira, independentemente da pequena repercussão das duas montagens e de seus evidentes nivelamentos interpretativos, para Gilda de Mello e Souza, elas deveriam ser louvadas simplesmente por se disporem a aceitar o desafio de encenar as peças longas de Tchékhov. Segundo a autora, nas peças longas do dramaturgo o risco da monotonia e do tom equivocado são frequentes. Por isso, por não se prenderem à pressão inicial dos prazos e bilheterias, Tchékhov poderia funcionar como um precioso professor, e suas peças seriam um excelente campo de pesquisa e treinamento para grupos estudantis e amadores. Ao invés do brilho individual, poderiam trabalhar o conjunto e buscar nuances nas ligações invisíveis que conectam e afastam cada uma das personagens. Ao invés do arrebatamento espetacular, típico dos melodramas, fariam o estudo detido e explorariam novos tons e sentidos mais profundos (MELLO E SOUZA, 1956). Desse modo, era como se o dramaturgo fosse passo essencial para o amadurecimento do nosso próprio teatro.

A essa altura, nos meios profissionais, o misto de veneração e desconhecimento que rondava as peças de Tchékhov era evidente. Seu subproduto era o medo real de encená-las, pois pareciam trazer problemas de difícil solução cênica. Se por um lado essa concepção trazia imperativos positivos, como a necessidade de maior amadurecimento do trabalho cênico e de ator, por outro 
cristalizava uma leitura que, como já vimos, restringia o potencial de suas peças e um diálogo mais potente com a própria realidade brasileira. Talvez por isso mesmo tenha sido um imigrante polonês, Ziembínski, quem conduziria a primeira encenação de uma peça longa de Tchékhov com um grupo profissional. Em 1960, o Teatro Nacional de Comédia (TNC) montou As três irmãs no Rio de Janeiro. O diretor emigrado, que já havia tido contato com o sistema de Stanislávski, valorizou uma espécie de cadência nas falas e movimentos e acentuou o drama vivido pelas irmãs. Contudo, ainda que respaldado por uma concepção que brilhava no exterior, o espetáculo fora duramente criticado por sua lentidão implacável - se fossem "reduzidas as grandes pausas na ação de representação e imprimido ritmo menos compassado ao desenrolar das cenas, estaria a obra mais dentro [...] da nossa compreensão de povo latino" (MAURICIO, 1960) - e pelo desnível do conjunto dos atores, algo aparentemente caro para um diretor que se espelhava no sistema de Stanislávski (MAGNO, 1960).

Tal montagem do TNC era apenas a expressão de uma imagem de Tchékhov que se tornou modelar e, ao mesmo tempo, ápice dessa forma de encená-lo. Se para alguns críticos perspicazes esse tchekhovismo era algo a se combater, para alguns atores, diretores e comentadores tal concepção era uma referência, já que ser "moderno" era estar em linha com as interpretações feitas no exterior. Dentro dessa perspectiva, pode-se dizer que os anos 1960 foram fundamentais, pois trouxeram o forte debate sobre o que significava modernizar o teatro brasileiro. Ser moderno seria reproduzir os padrões de dominação vigentes ou explorar as raízes locais e, portanto, "originais"? Assim, as próprias perguntas em relação a Tchékhov mudariam: seria o teatro brasileiro incapaz de encená-lo ou estaria o dramaturgo fora de sintonia com as demandas políticas daquele tempo?

Antonio Callado foi um dos primeiros a tentar dar um rumo a esse debate. Em uma série de artigos publicados no Correio da Manhã na década de 1960, ele afirmava que os paralelos entre a Rússia de Tchékhov e o contexto brasileiro eram abundantes: "as elites russas não eram elites nenhumas, os fazendeiros e senhores de engenho não eram nem maus nem bons, mas estúpidos e imprevidentes, todo o mundo via o errado de tudo, mas ninguém queria dar-se o trabalho de endireitar nada" (CALLADO, 1960). Segundo ele, o dramaturgo russo seria muito mais um cronista de técnica ficcional e dramatúrgica 
altamente moderna ("estilo câmera eye") do que o autor trágico e obscuro retratado por Stanislávski que, tendo feito sucesso, virou receita reproduzível em todo mundo. Daí os palcos, inclusive brasileiros, estarem repletos de "russismo": "atmosfera enfumaçada por samovares enormes, luz difusa, vozes estranguladas" (CALLADO, 1960). Para ele, Tchékhov deveria "ser servido nature, sem molho de Stanislávski” (CALLADO, 1960).

O ensaio de Antonio Callado, ainda que sintonizado com os pontos de vista mais engajados da época, não se concretizou de imediato nos palcos, e parece não ter sido convincente o suficiente a ponto de orientar as escolhas de grupos teatrais preocupados com as questões políticas do momento. As peças longas de Tchékhov, dado o peso da tradição cênica do tchekhovismo a elas conferido, ficariam fora do repertório dos grupos profissionais por oito anos após a montagem de 1960 do TNC. Yan Michalski chegaria a dizer, em 1968, que o senso-comum generalizado era o de que Tchékhov era um dramaturgo "ultrapassado" (MICHALSKI, 1968a). A saída proposta por ele viria em chave diferenciada da de Antonio Callado. Michalski aponta o quanto o dramaturgo russo é moderno por se utilizar ora do desencontro de linguagem (efeito imediato dos monólogos interiores e da impossibilidade do diálogo dramático), ora do efeito de simpatia ingênua que gera sobre uma personagem que, segundos depois, pode ser substituído pela sensação do ridículo. Ambos, combinados, gerariam um distanciamento do espectador que, sem poder identificar-se com tais personagens e situações, analisa criticamente o que ocorre. A matriz brechtiana de tal comentário é evidente.

É com essa chave que o crítico teatral analisa a encenação de Tio Vânia pelo Teatro de Comédia do Paraná (TCP), sob direção de Claudio Correia e Castro, em 23 de maio de 1968, em Curitiba. Para ele, o diretor conseguiu tirar de Tchékhov todo ritmo arrastado, toda autopiedade e todo sentimentalismo excessivos que marcaram as grandes encenações anteriores. Estabeleceu, ao contrário, "ritmo normal e descontraído", que seguia "as pulsações do texto" (Ibid.).

A encenação de Jardim das cerejeiras feita por Ivan Albuquerque meses depois, no Rio, seguiria a mesma direção apontada por essa montagem: a de rompimento com tal espécie de tchekhovismo. Para Michalski, aquele elenco, com irrisórios problemas, conseguiu atingir o "especialíssimo clima da peça, todo ele feito de meios-tons, de subentendidos, de ternura, de sorriso amargo, 
de gestos esboçados e não acabados" (Id., 1968b). A opção evidente de Ivan Albuquerque foi a de subverter a leitura stanislavskiana de Tchékhov e valorizar acima de tudo a comicidade da peça. Isso, segundo o diretor, já teria por si só efeito político decisivo naquela conjuntura árida.

Como se vê, nesse período diretores e críticos se debatiam para melhor entender as potencialidades críticas e políticas de Tchékhov no contexto brasileiro, com soluções nem sempre consensuais que resultavam de modo geral em polêmicas acaloradas. $E$ foi graças à iniciativa de um grupo igualmente polêmico que se deu um passo decisivo na trajetória de recepção do dramaturgo. Em 1972, o Teatro Oficina apresentou sua versão de As três irmãs. Seu ponto de partida já era totalmente diverso do que até então tinha sido feito:

enfim, nós decidimos tomar um ácido, uma pérola negra, e começamos a viajar pelo teatro todo até chegarmos num beco sem saída [...] e como eu estava pensando em As Três Irmãs, nós começamos a ler o texto e a descobrir o seu outro lado, a sua parte esotérica, a perceber que os seus quatro atos eram, também, quatro movimentos, 'quatro tempos'. (MARTINEZ CORRÊA, 1998, p. 230)

A parte "esotérica" do texto tchekhoviano era, definitivamente, um outro lado não explorado no Brasil e nas principais encenações europeias. Tal descoberta definiu o ritmo dos ensaios feitos na praia da Boraceia. Conceberam a cenografia como uma grande mandala e projetaram por todo o cenário imagens de relógios, pois para José Celso o tempo era o grande tema da peça. Como moldura geral, houve a tentativa de atualização de Tchékhov frente aos problemas de época: perpetrado o golpe militar de 1964, sendo perseguidas e massacradas as principais frentes de resistência de esquerda (armadas ou não), era preciso passar a limpo as teses de que "era preciso acumular forças" ou "esperar os bons tempos que virão" (como muitos militantes de esquerda resignados defendiam). A inteligência brasileira era comparada às irmãs: todas em compasso de espera (NASCIMENTO, 2012, p. 69-82).

Tal diretriz trazia soluções evidentes para a cena: pairava sobre os Prózorov a sensação de um forte julgamento - afinal, aquela família e seu entorno seriam os responsáveis por sua própria situação e, indiretamente, pela do mundo ao seu redor. Além disso, na encenação do dia 31 de dezembro de 1972, o $3^{\circ}$ ato se iniciava exatamente meia noite. Nesse ato, as três irmãs 
se deparam com um incêndio que toma conta do vilarejo, e Maria Fernanda (no papel de Olga) deveria entrar em cena, com um pequeno lenço vermelho, gritando: "fogo, fogo!". No entanto, automaticamente, como em um ritual (não previsto e não ensaiado), os atores começaram a se dirigir para o meio da plateia e para diversos pontos do palco, com inúmeras tochas. Criava-se um clima envolvente, místico, surgido da "necessidade dos corpos".

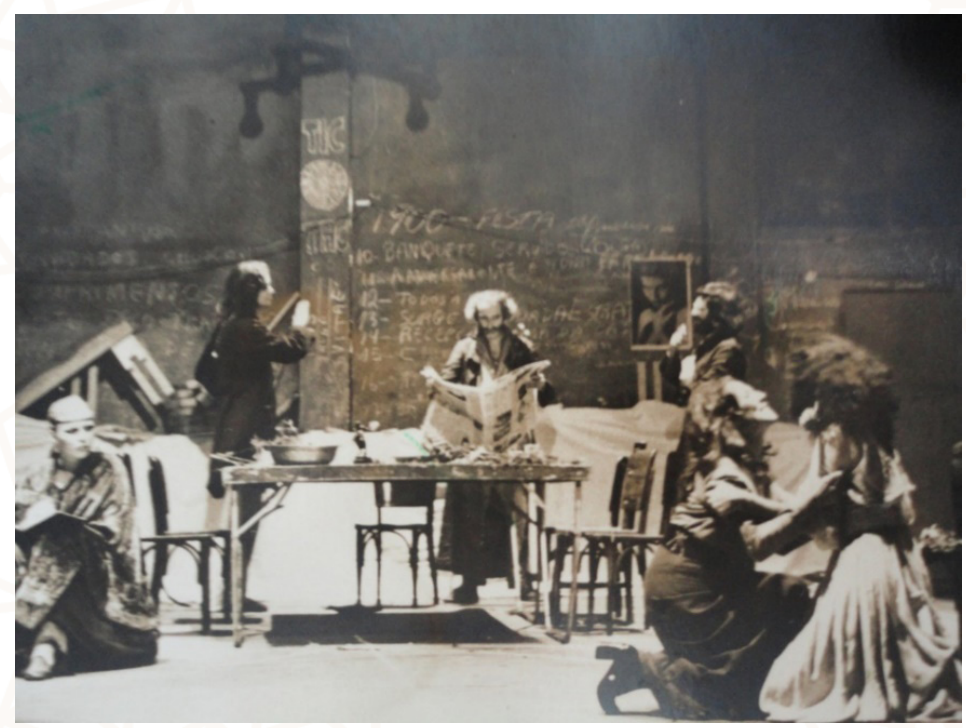

Figura 3 - Cena do primeiro ato. Inscrições como "Tic-Tac" na parede ao fundo. José Celso (como Tchebutikin) está no centro, com um jornal em mãos.

Foto: Fundo do Teatro Oficina, AEL-Unicamp, 1972.

Se tal "improviso" agradou sobremaneira a José Celso, que via ali o rumo a ser seguido pelo grupo, para Renato Borghi e atores como Othon Bastos, era a gota d'água: ao final, do meio da plateia, esse grupo de atores afirmou estar cansado de tais excessos e anunciou sua saída do espetáculo e da trupe, pois ainda acreditavam no "poder da palavra" e do teatro para dizer algo. Esta leitura de José Celso baseada no desbunde político e no "encontro dos corpos" dividiu o grupo e repercutiu de maneira negativa para boa parte da crítica, pois muitos comentadores viram ali um tom muito implacável e inconsequente em relação ao destino das irmãs. No entanto, alguns críticos, como Mariângela Alves de Lima, viram nesta montagem uma interpretação nova daquele drama de Tchékhov. Segundo ela, ao tentar trabalhar o russo dentro de um ritual esotérico, dentro de um jogo de corpos dançantes que provocava e convocava a plateia apática a pensar sobre si mesma e sua situação política, o Oficina tornava sua peça 
em uma leitura privilegiada da realidade brasileira. Ainda que com equívocos e julgamentos sumários feitos pelo diretor, Tchékhov funcionava dentro daquele contexto teatral e político específico, fazendo uma leitura do estágio vivido pela inteligência brasileira (LIMA, 1972).

Porém pode-se dizer que a encenação do Teatro Oficina reinaria isolada na década de 1970. Encenações como A gaivota, de Jorge Lavelli (Rio de Janeiro, 1974), tinham delicadeza e refinamento, mas não conseguiram lançar novas tendências interpretativas. Já nos anos 1980, a vida política brasileira dava seus sinais de regeneração com o surgimento de renovadas organizações operárias e camponesas, bem como de iniciativas teatrais de grupos caracterizadas pela produção coletiva e colaborativa em todos os níveis.

Nessa esteira surgiram direções arejadas, que valorizaram uma dimensão até então pouquíssimo explorada nas peças longas de Tchékhov: a comicidade. Assim foi com Platónov, peça dirigida por Maria Clara Machado, em 1980, no Rio. A diretora trabalhou, com os atores amadores, não o Tchékhov "pesadão, como as pessoas gostam de ver encenado" (COUTINHO, 1980), mas um Tchékhov leve, "mais travesso". Agregou a ele o que acreditava haver de "mineirice" (MARINHO, 1980) na temática de suas peças - aquilo que é decadente, falsamente importante e ao mesmo tempo simpático.

Do mesmo modo operou o espetáculo Trágico à força, de Márcio Aurélio (São Paulo, 1982), que tentou dar viés político às peças em um ato. O diretor estabeleceu para elas um fio condutor: o do casamento como expressão da opressão de Estado no nível familiar (LARA, 1982). Marcio Aurélio enxergava nessa problemática não só um fio que costurava todos os textos, mas também um dado de atualidade do dramaturgo. Em sua opinião, tratava-se de exacerbar questões que já soavam cômicas em fins do século XIX e que, agora, mereciam ser levadas ao grotesco: o interesse financeiro mesquinho que impera sobre os desejos e realizações e as imposições de um casamento opressivo sobre os anseios individuais.

Como se vê, já não se podia falar em recantos inexplorados de Tchékhov, seja do Tchékhov farsesco, seja do das quatro peças maiores. Entre uma e outra encenação, entre altos e baixos, já não há tendência cômica ou trágica, naturalista ou vanguardista que não tenha sido investigada. Assim, Tchékhov paulatinamente passava a fazer parte do repertório dos grandes grupos. 
A partir de meados da década de 1980 e ao longo da década de 1990, começa a ficar difícil o mapeamento e mesmo a discussão crítica aprofundada sobre as principais encenações de Tchékhov feitas Brasil afora. As quase quarenta encenações mapeadas nesse período (ver listagem ao final) giravam em torno de três grandes leituras das peças do autor: Tchékhov universalista, engajado ou desconstruído.

No quadro desse Tchékhov universalista, leitor da "alma humana", figuram as encenações realizadas pelo Teatro dos Quatro, encabeçado por Sérgio Britto e Paulo Mamede (Tio Vânia, em 1984, e Jardim das cerejeiras, em 1989), que se caracterizavam por: valorização do cômico, eliminação do clima grandiloquente e do ritmo lento, e tentativa de "mostrar que o ser humano é atemporal, eterno, pois apesar das fantásticas conquistas técnicas e científicas feitas até hoje, o homem e a mulher continuam a procura de uma conquista: o outro" (CEZIMBRA, 1989). Na mesma linhagem também esteve a montagem de $A$ gaivota, dirigida por Chico Medeiros, em 1994, e A gaivota, por Jorge Takla, em 1996. Por fim, temos a peça Tio Vânia, dirigida por Aderbal Freire-Filho em 2003, no Rio de Janeiro, que apresentou uma inovadora direção nos jardins do Parque Lage. Freire-Filho optou por uma direção que não poluísse o texto e desse destaque ao "caráter humano", fugindo da "tradicional melancolia" impressa em muitas montagens do dramaturgo (ALMEIDA, 2003).

Como outra vertente desse período, encontramos as leituras que valorizaram a dimensão crítica ou mesmo política do dramaturgo. Élcio Nogueira Seixas, em sua direção de Tio Vânia (Curitiba, 1998) e de Jardim das cerejeiras (São Paulo, 2000), explorou um Tchékhov leve, cômico, mas ao mesmo tempo leitor agudo das desigualdades e contradições de seu tempo. Assim Mariângela Alves de Lima (1998) avaliou a montagem de Tio Vânia:

Uma peça de Tchékhov dilacerada, em alta voltagem, sugerindo mais a explosão do que o ponto final, escapa certamente às concepções canônicas do mundo tchekhoviano. E é bom ver, neste espetáculo que exalta e poetiza o caos que se segue à desilusão, que há nessas magníficas peças, latentes, coisas inexploradas.

Do mesmo modo, o Ivánov (Curitiba, 1998) de Eduardo Tolentino tinha em vista iluminar o seu próprio processo de pesquisa sobre a realidade 
brasileira. Ainda que o diretor declarasse abertamente não intencionar um espetáculo político, acreditava ao mesmo tempo que a simples apresentação dessa peça de Tchékhov sugeriria os paralelos políticos necessários. Isso porque o clima de desmotivação que cercava Ivánov seria o mesmo do neoliberalismo dos anos 1990 (GUZIK, 1998). Na mesma chave, o Tio Vânia de Celso Frateschi (São Paulo, 2000) se propunha a um espetáculo limpo e direto. $O$ diretor acreditava que, pela simples força do texto tchekhoviano, o espectador faria os paralelos com a realidade brasileira de fim de século, marcada por polarizações e pela espera de mudanças sociais que não ocorrem.

Por fim, de meados dos anos 1990 até agora emergiram de modo mais intenso montagens que passaram a se interessar pela desconstrução das peças do dramaturgo, ou do que tradicionalmente se pensou sobre elas. Em sintonia com as pesquisas teatrais contemporâneas, reverberações diretas das pesquisas de Artaud, Grotowsky e Eugenio Barba, tais espetáculos buscam especificar o material da linguagem teatral e exploram mais a fundo a construção de significados por meio do trabalho dos atores com seu próprio corpo, objetos e recursos multimídia. Dentro desse universo livre das amarras convencionais, a atualização do dramaturgo já não se dá pela ideia de que o texto por si só terá algo a dizer e será sensível às demandas do nosso tempo. Por isso, muitas montagens desse período buscaram a própria explosão da tessitura do drama para abri-la a um sem número de significações possíveis que ficam por conta do espectador. Isso se dá ora pela eliminação de personagens, ora pelo rompimento com qualquer cronologia ou causalidade, ou mesmo pelo enfrentamento direto de ritmos que porventura pudessem ser sugeridos pela dramaturgia original. Muitas vezes, interessa mais a construção que se faz no presente sobre a peça do que partir desta para pensar o presente. Em outras palavras, trata-se mais de uma construção sobre Tchékhov que de Tchékhov.

É o que se viu, por exemplo, nas montagens de As três irmãs de Bia Lessa (Rio de Janeiro, 1998) e de Enrique Diaz (Rio de Janeiro, 1999). Ambas buscaram o rompimento com o padrão naturalista de encenação, utilizaram-se de inúmeros recursos multimídia, trabalharam a fisicalidade dos atores e exploraram pontos de conexão entre as personagens e experiências pessoais dos atores, que eram trazidas para o palco. Bia Lessa, por exemplo, 
impregnou-se do máximo de naturalismo para negá-lo. Para isso, realizou os ensaios da peça em um grande casarão em Santa Tereza, no Rio de Janeiro, no qual os atores tinham de atuar como que realizando tarefas cotidianas dentro de casa: lavando pratos, escovando os dentes, tomando banho... Isso, em sua opinião, teria o efeito decisivo de tirar o glamour de Tchékhov e de torná-lo mais próximo de nosso dia a dia (AS TRÊS..., 1998).

Mas o ponto alto da desconstrução do teatro de Tchékhov está no espetáculo Gaivota, tema para um conto curto, de Enrique Diaz (Rio de Janeiro, 2006), que pode ser considerado momento decisivo dessa etapa da recepção do russo. A intenção de Diaz não era representar Tchékhov como ele foi encenado no século XIX, mas apresentar uma encenação intencionalmente inacabada, a fim de valorizar as angústias, dificuldades e problematizações que giram em torno do processo de produção - como se vê, um enfrentamento direto às noções stanislavskianas. Por isso, ao longo da encenação o palco estava nu, a fim de limpar a cena do peso realista e ceder espaço para que essa mistura de temporalidades (da fábula de Tchékhov e dos quase 110 anos da escrita da peça) e de materiais (do conjunto de experiências, problematizações e signos que são trazidos do processo de pesquisa) pudesse operar. Assim entendemos o foco dado pelo grupo ao problema da encenação fracassada de Trepliov no primeiro ato e ao problema da passagem do tempo, expressa no conflito entre gerações (Arkádina versus Trepliov, realismo versus simbolismo). Os atores indagavam o público sobre o que significava estarem ali, distantes tantos anos daquele dramaturgo, ou se perguntavam se os riscos de sua encenação fracassar não eram os mesmos que rondaram Trepliov na peça de Tchékhov, ou o fracasso da primeira estreia de $A$ gaivota no Aleksandrínski em fins do século XIX.

Nessa montagem, o tempo da fábula é deixado de lado e, quando aparece, sua importância está em pé de igualdade com outras temporalidades. Todos esses elementos exigem um outro grau de participação do público, que não pode mais esperar uma absorção catártica e a apresentação de respostas a problemas vindos de antemão (RAMOS; FERNANDES, 2007, p. 225228.). A montagem, feita para iniciados no mundo do teatro e com forte teor metalinguístico, buscava compreender a gramática do texto tchekhoviano e os sentidos que ele abre para o próprio ator. Por isso predominou no espetáculo 
o jogo de alternância entre a primeira e a terceira pessoas do discurso na fala de um mesmo ator, algo que joga com a transitoriedade da condição da personagem e a analisa. Tais procedimentos orientaram esse espetáculo, que vê a atualização do dramaturgo a partir da incorporação na tessitura de seu drama do processo de elaboração da encenação. Isso significa trazer para o espetáculo todas as dúvidas, angústias, problematizações e relações trabalhadas no processo de pesquisa, resultando em um "mal acabado produto final." Do mesmo modo, significa trazer para o espetáculo as questões relativas ao que quer dizer voltar a essa obra, ou atualizá-la, passado praticamente um século de sua escrita. Para Ramos e Fernandes, desse modo o espetáculo "se torna tão ou mais fiel ao original" (Ibid., loc. cit.).

Após a aclamada encenação de Enrique Diaz, inúmeras foram as montagens de Tchékhov que continuaram a marcar os palcos brasileiros. E, à medida que avançam os anos, torna-se difícil mapeá-las e discuti-las a contento - seja porque já não se pode dizer que as principais montagens aconteçam exclusivamente nas capitais, seja porque Tchékhov tem se tornado nome comum nos cursos de artes cênicas e no repertório de boa parte das companhias.

Ao longo dos anos, muitos acreditaram que seria possível escrever um estudo definitivo sobre a poética dramática de Tchékhov. Agora, livres do impulso de encontrarmos uma possível verdade do texto, pretensamente a-histórica e universal, percebemos que o interesse e o fascínio pelas peças do dramaturgo russo estão justamente em sua forma aberta. A estrutura dramática desamarrada e o estilo irônico e objetivo - que tornam a identificação com cada personagem sempre ambígua e enganosa - criaram peças fronteiriças difíceis de serem imediatamente associadas a esta ou aquela estética. Muito provavelmente disso advém a capacidade das peças de Tchékhov atravessarem diferentes culturas ao longo do tempo, atualizando-se e gerando significados tão polêmicos e potentes no palco. Pudera o próprio Tchékhov estar vivo para saber que seus textos não durariam poucos anos, como ele imaginava, mas atravessariam o século e calariam fundo na história do teatro brasileiro.

\section{Lista de montagens das peças de Tchékhov (1946-2008) 1946 - O urso. Hermilo Borba Filho / TEP, Recife. 1949 - Festival Tchekhov. Guilhermino César / TERGS, Porto Alegre.}


1950 - Um pedido de casamento. Adolfo Celi / TBC, São Paulo. 1950 - Um pedido de casamento. Adacto Filho / TAF, Salvador. 1951 - Um pedido de casamento. Osmar R. Cruz / Clube de Teatro, SP. 1952 - Um pedido de casamento. Ruggero Jacobbi / EAD, Recife. 1952 - Um pedido de casamento. Expedito Pôrto / TEPCE, Rio de Janeiro. 1952 - O urso/Um pedido de casamento. Agremiação Goiânia de Teatro, Goiânia. 1953 - Festival Tchékhov. Nina Ranevsky, Rio de Janeiro. 1954 - Um pedido de casamento. Ziembínski/ TBC, São Paulo. 1954 - Um pedido de casamento. Adolfo Celi / TBC. 1955 - Tio Vânia. Geraldo Queiroz / O Tablado, Rio de Janeiro. 1956 - As três irmãs. Alfredo Mesquita / EAD, Ribeirão Preto. 1957 - Um pedido de casamento. S. de Paiva / TRE, DF, Rio de Janeiro. 1958 - O jubileu. Rubens Corrêa / O Tablado, Rio de Janeiro 1958 - As três irmãs. Gianni Ratto / A Barca, Salvador. 1960 - As três irmãs: Ziembínski / TNC, Rio de Janeiro. 1962 - Anton Tchékhov - um festival. Luiz Carlos Maciel / A Barca, Salvador. 1962 - Tio Vânia. Alberto D’Aversa / EAD, São Paulo. 1962 - Um pedido de casamento. Luiz Nagib Amary / Belo Horizonte. 1964 - Festival Tchecov. Sérgio Mibielle / Belo Horizonte. 1966 - Um pedido de casamento/O Aniversário. Cláudio Heemann / CAD, Porto Alegre.

1966 - O pedido de casamento. Maria H. Magalhães, Rio de Janeiro. 1966 - Pedido de casamento. Grupo André Luiz, Marília. 1967 - Um pedido de casamento/O jubileu. Dulcina de Moraes / FBT, Rio de Janeiro.

1967 - As três irmãs. Haydée Bittencourt, Belo Horizonte. 1968 - Tio Vânia. Cláudio Correa e Castro / Curitiba. 1968 - Jardim das cerejeiras. Ivan de Albuquerque / Grupo do Rio, Rio de Janeiro. 1969 - Trágico à força/O urso. João Ribeiro Chaves / Grupo Casarão, São Paulo. 1972 - As três irmãs. José Celso Martinez Correa / Oficina, São Paulo. 1974 - A gaivota. Jorge Lavelli / Rio de Janeiro. 1974 - Tio Vânia. Álvaro Guimarães / Salvador. 1975 - O jubileu. Beto Diniz / Rio de Janeiro. 1975 - Um pedido de casamento. J. B. Galvão / ATARD, Brasília (DF). 
1975 - Tio Vânia. Emilio Di Biasi / Grupo Heros, São Paulo.

1976 - Um pedido de casamento/O urso/Sobre os Males que traz o Tabaco. TECA / Araraquara.

1976 - O urso. José Guilherme de Castro Alves/Vitória.

1977 - O Casamento de Natalina (adap.).Carlos Augusto Strazzer / São Paulo.

1977 - Pedido de casamento/O urso. Pedro Marcos / Grupo Anhangá, São Paulo. 1980 - Platónov. Maria Clara Machado / O Tablado, Rio de Janeiro.

1982 - Jardim das cerejeiras. Jorge Takla / São Paulo.

1982 - O trágico à força. Marcio Aurélio / São Paulo.

1982 - O pedido de casamento. Adalberto Nunes / Rio de Janeiro.

1984 - Jardim das cerejeiras. Lala Schneider / Curitiba.

1984 - Tio Vânia. Sérgio Britto / Teatro dos Quatro, Rio de Janeiro.

1984 - Irresistível aventura (adap.). Domingos Oliveira / Rio de Janeiro.

1988 - Os males que o fumo produz. Ronaldo Brandão / Belo Horizonte.

1988 - O urso. Antonio Oliveira / Porto Alegre.

1988 - Lago 21 (adap.). Jorge Takla / São Paulo.

1988 - Pedido de casamento. Elpídio Navarro / João Pessoa.

1989 - Tio Vânia. Celso Frateschi / EAD-USP, São Paulo.

1989 - Um pedido de casamento. Roberto Parkinson, Brasília (DF).

1989 - Jardim das cerejeiras. Paulo Mamede / Teatro dos Quatro, Rio de Janeiro.

1989 - A gaivota. Luiz Paulo Vasconcellos, Porto Alegre.

1990 - Jardim das cerejeiras. Antonio Cadengue / Cia de Teatro Seraphim, Recife.

1991 - A proposta (adap.). Rodolfo García Vázquez / Os Satyros, São Paulo. 1992 - Seraphins Revisões - Jardim das cerejeiras. Antonio Candengue / Cia de Teatro Seraphin, Recife.

1994 - A gaivota. Chico Medeiros /Cia. Bexiga, São Paulo.

1995 - A gaivota. David Herman / Rio de Janeiro.

1996 - A gaivota. Jorge Takla / Rio de Janeiro.

1996 - Um pedido de casamento. Marcus Alvisi / Rio de Janeiro.

1998 - Tio Vânia. Élcio Nogueira Seixas / Teatro Promíscuo, Curitiba.

1998 - O urso. José Henrique / Rio de Janeiro.

1998 - Ivanov. Eduardo Tolentino / Tapa, Curitiba.

1998 - Da gaivota. Daniela Thomas / Curitiba. 
1998 - As três irmãs. Bia Lessa / Rio de Janeiro.

1999 - As três irmãs. Enrique Diaz / Rio de Janeiro.

2000 - Tio Vânia. Celso Frateschi / Grupo Ágora, São Paulo.

2000 - Jardim das cerejeiras. Élcio Nogueira Seixas / São Paulo.

2002 - A proposta (adap.). Os Satyros / São Paulo.

2003 - Tio Vânia. Aderbal Freire-Filho / Rio de Janeiro.

2006 - Gaivota - tema para um conto curto. Enrique Diaz / Cia dos Atores, Rio de Janeiro.

2007 - A Farsa (adap.). Luis Artur Nunes/ Porto Alegre.

2008 - Jardim das cerejeiras. Moacir Chaves / Rio de Janeiro.

2008 - Tio Vânia. Celso Frateschi / Grupo Ágora. São Paulo.

\section{Referências bibliográficas}

ALMEIDA, R. Infelizes para sempre. Jornal do Brasil, Rio de Janeiro, 12 jun. 2003.

ANIKST, A. Teoria dramy v Rossii ot Púchkina do Tchékhova. Moscou: Nauka, 1972.

AS TRÊS irmãs retrata cotidiano. Folha de S.Paulo, São Paulo, 9 out. 1998.

CALLADO, A. Chekov. Correio da Manhã, Rio de Janeiro, 8 set. 1960.

CEZIMBRA, M. Comédia da decadência. Jornal do Brasil, Rio de Janeiro, 25 jul. 1989.

COUTINHO, W. N. Leveza Russa - Tchekov encenado do modo como ele preferia. Veja, São Paulo, 4 jun. 1980.

FESTIVAL TCHÉKHOV. Grupo A Barca. Programa da Peça. Salvador, abr. 1962.

FRANCIS, P. Opinião Pessoal (Cultura e Política). Rio de Janeiro: Civilização Brasileira, 1966.

GUZIK, A. Grupo TAPA aproxima Chekhov do Brasil atual. Jornal da Tarde, São Paulo, 16 abr. 1998.

LARA, P. Obras de Checov num só espetáculo. Folha da Tarde, São Paulo, 23 jun. 1982.

LEITE, L. B. O jardim das cerejeiras. Jornal do Comércio, Rio de Janeiro, 27 out. 1968.

LIMA, M. A. Há algo de inexplorado em 'Tio Vânia'. O Estado de S. Paulo, São Paulo, 24 abr. 1998.

1972.

MACIEL, L. C. O jardim das cerejeiras. O Paiz, Rio de Janeiro, 9 nov. 1968. 
MAGARSHACK, D. Chekhov the Dramatist. London: John Lehmann, 1952.

MAGNO, P. C. 'As Três Irmãs', no Serrador. Correio da Manhã, Rio de Janeiro, 16 jan. 1960.

MARINHO, F. Retrato de uma raça. No Tablado, Tchecov estreante. O Globo, Rio de Janeiro, 24 maio 1980.

MARTINEZ CORRÊA, J. C. Primeiro ato: cadernos, depoimentos, entrevistas (19591972). São Paulo: Editora 34, 1998.

MAURICIO, A. As três irmãs. Jornal do Brasil, Rio de Janeiro, 9 fev. 1960.

MELLO E SOUZA, G. As três irmãs. O Estado de S. Paulo, São Paulo, 13 out. 1956.

Suplemento Literário do Estado de S. Paulo.

MICHALSKI, Y. As três irmãs: vítimas ou culpadas? Jornal do Brasil, Rio de Janeiro, 16 jan. 1973.

. Tchecov em Curitiba (I). Jornal do Brasil, Rio de Janeiro, 4 jun. 1968a. Caderno B, p. 2.

Um jardim florido e amigo (I). Jornal do Brasil, Rio de Janeiro, 20 out. 1968b. . Um jardim florido e amigo (II). Jornal do Brasil, Rio de Janeiro, 23 out. 1968c.

NASCIMENTO, R. A. O encontro de Tchékhov com o Oficina: desbunde, política e algumas contradições. Revista de Literatura e Cultura Russa, São Paulo, v. 1, n. 1, p. 69-82, 2012. http://dx.doi.org/10.11606/issn.2317-4765.rus.2012.88683

Tchékhov no Brasil: a construção de uma atualidade. 2013. $344 \mathrm{f}$. Dissertação (Mestrado em Literatura e Cultura Russa) - Faculdade de Filosofia Letras e Ciências Humanas, Universidade de São Paulo, São Paulo, 2013a.

Tchékhov no Ocidente: entre o exótico e o íntimo. Aspas, São Paulo, v. 3,

n. 1, p. 105-125, 2013b. http://dx.doi.org/10.11606/issn.2238-3999.v3i1p105-125

NEMIRÓVITCH-DÂNTCHENKO, V. My life in the Russian Theatre. Boston: Little, Brown, and Co, 1937.

Prefácio. In: ÉFROS, N. Tri sestry v postanovkie Moskovskovo Khudojestvienovo teatra. Petrogrado, 1919.

PRADO, D. A. Entre quatro paredes e O pedido de casamento. In: Apresentação do

Teatro Brasileiro Moderno: 1947-1955. São Paulo: Martins, 1956.

Peças, pessoas, personagens: o teatro brasileiro de Procópio Ferreira a

Cacilda Becker. São Paulo: Companhia das Letras, 1993.

RAMOS, L. F.; FERNANDES, S. Diálogo da gaivota. Sala Preta, São Paulo, v. 7,

p. 225-228, 2007. http://dx.doi.org/10.11606/issn.2238-3867.v7i0p225-228

TEATRO BRASILEIRO DE COMÉDIA. Encarte. São Paulo, 1954.

TIO VÂNIA e seu diretor. Jornal do Brasil, Rio de Janeiro, 8 dez. 1955.

Recebido em 24/09/2017

Aprovado em 03/05/2018

Publicado em 29/28/2018 